\title{
Enhancement of periodontal tissue regeneration by conditioned media from gingiva-derived or periodontal ligament- derived mesenchymal stem cells: a comparative study in rats
}

Jiling Qiu 1,2,3, Xiaotong Wang 1,2,3, Haowen Zhou 1,2,3, Chunshu Zhang ${ }^{2,3}$, Yijia Wang ${ }^{1,2,3}$, Jiahui Huang ${ }^{1,2,3}$, Meng Liu ${ }^{1,2,3}$, Pishan Yang ${ }^{1,2,3^{*}}$ and Aimei Song ${ }^{1,2,3^{*}}$ (i)

\begin{abstract}
Background: Evidence has demonstrated conditioned medium (CM) from periodontal ligament stem cells (PDLSCS) improved periodontal regeneration. Gingival mesenchymal stem cells (GMSCs) have been considered an alternative strategy for regenerative medicine. To determine whether GMSC-CM could promote periodontal wound healing, we compared the effects of GMSC-CM and PDLSC-CM on periodontal regeneration and the underlying mechanisms in rat periodontal defects.
\end{abstract}

Methods: Cell-free CMs were collected from PDLSCs, GMSCs, and gingival fibroblasts (GFs) using ultracentrifugation (100-fold concentration). Periodontal defects were created on the buccal side of the first molar in the left mandible of 90 rats by a surgical method. Collagen membranes loaded with concentrated CMs (a-MEM, GF-CM, GMSC-CM, PDLSC-CM) were transplanted into periodontal defects. After 1, 2, and 4 weeks, the animals were sacrificed and specimens including the first molar and the surrounding tissues were separated and decalcified. Hematoxylin-eosin and Masson's trichrome staining were performed to evaluate periodontal regeneration. Immunohistochemical staining for tumor necrosis factor (TNF)- $\alpha$, interleukin (IL)-1 $\beta$, and IL-10 was conducted to analyze inflammation. Immunohistochemistry of BSP-II and Runx2 was performed to analyze osteoblast differentiation.

Results: Histological analysis showed the amount of newly formed periodontal tissue was significantly higher in both the GMSC-CM and PDLSC-CM groups than in the other groups, with no significant difference between these two groups. At 1 and 2 weeks, the expression levels of TNF- $\alpha$ and IL-1 $\beta$ were significantly lower in the GMSC-CM and PDLSC-CM groups than in the other three groups, while there was no significant difference between these two groups. IL-10 expression was significantly higher in the GMSC-CM group than in the PDLSC-CM group and the other three groups. At 1, 2, and 4 weeks, BSP-II and Runx2 expressions were significantly higher in the GMSC-CM and PDLSC-CM groups than in the other three groups, with no significant difference between the two groups.

(Continued on next page)

\footnotetext{
* Correspondence: yangps@sdu.edu.cn; sam1972@sdu.edu.cn

${ }^{1}$ Department of Periodontology, School and Hospital of Stomatology,

Shandong University, No.44-1 Wenhua Road West, Jinan 250012, Shandong,

China

Full list of author information is available at the end of the article
}

(c) The Author(s). 2020 Open Access This article is distributed under the terms of the Creative Commons Attribution 4.0 International License (http://creativecommons.org/licenses/by/4.0/), which permits unrestricted use, distribution, and reproduction in any medium, provided you give appropriate credit to the original author(s) and the source, provide a link to the Creative Commons license, and indicate if changes were made. The Creative Commons Public Domain Dedication waiver (http://creativecommons.org/publicdomain/zero/1.0/) applies to the data made available in this article, unless otherwise stated. 
(Continued from previous page)

Conclusions: Our results demonstrate that GMSC-CM transplantation can significantly promote periodontal regeneration in rats and achieve the same effect as PDLSC-CM. The mechanism of periodontal regeneration may involve the regulation of inflammatory factors and the promotion of osteogenic differentiation of bone progenitor cells in the wound region by CMs from MSCs.

Keywords: Gingiva-derived mesenchymal stem cells, Periodontal ligament stem cells, Conditioned medium, Periodontal regeneration, Rats

\section{Background}

Periodontitis is a chronic inflammatory disease that involves the destruction of connective tissue attachments and alveolar bone resorption [1]. Progressive destruction of alveolar bone supporting teeth can lead to tooth loosening and displacement, gingival recession, and eventually tooth loss [2]. In China, the incidence of periodontitis among adults over 35 years old is up to $40 \%$. The ultimate goal of treatments for periodontitis is the regeneration of damaged periodontal tissue $[3,4]$.

Mesenchymal stem cells (MSCs) are nonhematopoietic stromal cells that can be isolated from various adult tissues, such as the bone marrow, placental, adipose, umbilical cord, periodontal ligament, and gingival tissue $[5,6]$. The capacity of MSCs to differentiate into multipotent cells $[7,8]$ has advanced them to the forefront in regenerative medicine [9, 10]. An increasing number of reports have indicated that, apart from their multi-differentiation potential, the paracrine pathway might be the principal mechanism by which MSCs contribute to tissue regeneration $[11,12]$.

Conditioned medium generated by MSC culture contains growth factors, cytokines, and other active substances [13]. MSC-CM transplantation, as a cell-free technique, is more convenient and safer to apply and has much greater potential for clinical translation than MSC transplantation [14, 15]. A variety of studies have indicated that MSC-CM has immunomodulating, angiogenesis-promoting, and cell growth-supporting properties, and MSC-CM has been reported to enhance regeneration in many animal wound models [16], including periodontal defect models $[17,18]$.

Periodontal ligament stem cells (PDLSCs), as the adult stem cell population in tooth-supporting tissues [19], are the most widely studied and used for periodontal tissue regeneration [20, 21]. Transplantation of PDLSC-CM has been documented to result in considerable new connective attachment and alveolar bone formation. However, to obtain PDLSCs in vitro, multiple periodontal membranes of extracted teeth are required, and the success rate of culture is very low [22]. A long amount of time ( 1 to 2 months) is required to obtain the large number of PDLSCs necessary for in vivo transplantation [23, 24]. Therefore, the widespread application of PDLSCs in periodontal therapy is severely influenced due to its limited access.
Therefore, we sought to explore CMs from other stem cells for use in regenerating lost periodontal tissue. Gingivaderived mesenchymal stem cells (GMSCs) can be isolated from gingival connective tissue and have been confirmed to have a self-renewal capacity, multi-differentiation potential, and strong immunomodulatory properties [25]. GMSCs are more readily available than PDLSCs and other MSCs due to their abundant sources without requiring tooth extraction $[26,27]$. The gingiva collection procedure is minimally invasive and enables scarless wound healing [28]. Moreover, some studies have shown that GMSCs have superior antiinflammatory and immunomodulatory functions [29, 30]. There have been reports indicating that transplantation of GMSCs contributes to bone tissue regeneration in animal bone defect models [31, 32] and periodontal regeneration [33]. Thus, GMSCs may be promising for use in future regenerative medicine as a readily available stem cell source.

Although there are a few reports involving the transplantation of GMSC-CM for tissue regeneration [34, 35], its use in periodontal regeneration has not been reported. Therefore, in this study, we compared the effect of GMSC-CM on periodontal regeneration and the underlying mechanism with the effect of PDLSC-CM by using a periodontal defect model in rats, aiming to provide a theoretical basis for the application of GMSC-CM in periodontal regeneration in the future.

\section{Methods}

\section{Tissue sources}

Healthy gingival tissue samples were obtained from three donors (18 to 25 years old) who provided informed consent undergoing mandibular third molar extraction at the Hospital of Stomatology, Shandong University. Tissue specimens were collected following the approval of $\mathrm{Hu}$ man Research Projects, the Ethics Committee of School of Stomatology, Shandong University (No. GR201407).

\section{Cell culture}

\section{Human GMSC culture and identification}

Human GMSCs were isolated from healthy gingival tissues by the finite dilution method according to the report by $\mathrm{Du}$ [36]. Briefly, each gingival tissue sample was diced into 1$\mathrm{mm}^{3}$ pieces, and culture medium was added. Approximately 7 to 10 days later, spindle-like cells grew out from 
the tissues, and the cells were collected with trypsin. Individual cells were plated in 10-cm culture dishes $(3300$ cells/dish). After 10 to 15 days, single-cell-derived colonies were collected and subcultured. Passage 4 cells were used for GMSC identification and the following experiments. During the experiment, cells were cultured in $\alpha$-minimal essential medium ( $\alpha$-MEM; Sigma-Aldrich, St. Louis, MO, USA) containing $20 \%$ fetal bovine serum (FBS; Biological Industries, Kibbutz Beit-Haemek, Israel), $100 \mathrm{U} / \mathrm{ml}$ penicillin, and $0.1 \mathrm{mg} / \mathrm{ml}$ streptomycin at $37^{\circ} \mathrm{C}$ with $5 \% \mathrm{CO}_{2}$. The complete medium was replaced every 3 days.

\section{Characterization of GMSCs}

For MSC-associated surface antigen identification, the above cells were detached into single-cell suspensions $\left(10^{6} /\right.$ $\mathrm{ml}$ ) in phosphate-buffered saline (PBS) and then incubated with fluorescein isothiocyanate-conjugated mouse monoclonal antibodies $(10 \mu \mathrm{g} / \mathrm{ml})$ specific for human CD35, CD45, CD90, CD105, and CD44 (BioLegend, San Diego, CA, USA) for $1 \mathrm{~h}$ on ice away from light. The cells were then washed with PBS, and the suspensions were subjected to flow cytometry (BD Biosciences, Franklin Lakes, NJ, USA).

For multidifferential potential identification, cells were cultured in osteogenic $\left(1 \times 10^{-8} \mathrm{~mol} / \mathrm{l}\right.$ hexadecadrol, 5 $\mathrm{mmol} / \mathrm{l}$ sodium $\beta$-glycerophosphate, $50 \mathrm{mg} / \mathrm{l}$ vitamin $\mathrm{C}$, and $10 \% \mathrm{FBS}$ in $\alpha$-MEM) or adipogenic $(0.5 \mu \mathrm{mol} / \mathrm{l}$ hexadecadrol, $60 \mu \mathrm{mol} / \mathrm{l}$ indomethacin, $0.5 \mathrm{mmol} / \mathrm{l}$ isobutyl methylxanthine, $10 \mathrm{mg} / \mathrm{l}$ bovine insulin, and 10\% FBS in $\alpha$-MEM) media for 28 and 21 days with the media changed every 3 days. Cells were then washed with PBS three times and fixed in $4 \%$ paraformaldehyde. Osteogenic cultures were stained with Alizarin Red (Solarbio, Beijing, China), and adipogenic cultures were stained with Oil Red O (Solarbio).

\section{Human gingival fibroblast culture}

Instead of the limiting dilution method for GMSCs, cells growing out from the cultured gingival tissue were collected with trypsin and subcultured six times. Gingival fibroblasts (GFs) were obtained at passage 7 .

\section{PDLSC culture}

PDLSCs for isolation and culture were kindly provided by Chunshu Zhang [37].

\section{Preparation and concentration of CMs}

GMSCs, PDLSCs, and GFs were cultured to $80 \%$ confluency in $10 \%$ FBS complete medium. Then, the medium was replaced by serum-free $\alpha-M E M$, and the cells were cultured for another $48 \mathrm{~h}$ at $37^{\circ} \mathrm{C}$ under $5 \% \mathrm{CO}_{2}$. The supernatants of the GMSC, PDLSC, and GF groups were collected, centrifuged at $173 \mathrm{~g}$ for $5 \mathrm{~min}$, and then passed through $0.22-\mu \mathrm{m}$ filters to obtain CMs. Then, the acquired CMs were concentrated 100-fold using ultrafiltration centrifuge tubes (Ultra-15 $10 \mathrm{kD}$ centrifugal filter, EMD Millipore, Billerica, MA, USA) at $5000 \mathrm{~g}$ and $4{ }^{\circ} \mathrm{C}$ for 40 min according to the manufacturer's instructions. Control $\mathrm{CM}$ was collected from serum-free $\alpha$-MEM, incubated for $48 \mathrm{~h}$ at $37^{\circ} \mathrm{C}$ under $5 \% \mathrm{CO}_{2}$, and concentrated as mentioned above. Then, the bicinchoninic acid (BCA) (Solarbio) method was used to determine the protein concentration in the CMs. All concentrated CMs were subpackaged and stored at $-80^{\circ} \mathrm{C}$.

\section{Animal experiment}

\section{Experimental animals}

Ninety male Wistar rats (6 to 7 weeks of age, weighing 200 to $230 \mathrm{~g}$ ) were procured from the Experimental Animal Center, Shandong University. Rats were housed in individual ventilated cages and provided ad libitum access to both food and water. After 1 week, rats were allocated randomly into five groups: a control group, an $\alpha$-MEM group, a GFCM group, a GMSC-CM group, and a PDLSC-CM group, for the subsequent study. All animal experiments were approved by the Ethics Committee of School of Dentistry, Shandong University (No. GD201714).

\section{Establishment of the rat periodontal defect model}

After 1 week of acclimation, rats were anesthetized with an intraperitoneal injection of pentobarbital sodium (40 $\mathrm{mg} / \mathrm{kg}$ ). The periodontal defect model was established according to Nagata et al. [17] with slight modification of the root surface treatment. Briefly, the left mandible buccal plate was exposed through an extraoral incision. Then, the buccal bone, horizontally from the mesial root of the first mandibular molar to the mesial root of the second mandibular molar and vertically from the most coronal aspect of the alveolar crest to the apical root, was carefully removed by turbomachinery to expose the surfaces of the mesial, middle, and distal roots of the first molar. Specifically, all exposed root surfaces were completely debrided with a mini-Gracey curette (Hu-Fridy, USA) to remove the periodontal ligament and the cementum. The defect was approximately $3 \mathrm{~mm}$ wide, $2 \mathrm{~mm}$ in height, and $1 \mathrm{~mm}$ in depth (see Additional file 1).

\section{Transplantation of conditioned media}

After the defects were thoroughly rinsed with sterilized normal saline, blood was fulfilled. Each defect received one type of $\mathrm{CM}$ loaded with resorbable collagen scaffolds (Bio-Gide, Geistlich Biomaterials, Wolhusen, Switzerland). The collagen membrane was cut to a size of $2 \mathrm{~mm} \times 3 \mathrm{~mm}$ and immersed in concentrated $\alpha$-MEM, GF-CM, GMSC-CM, or PDLSC-CM for $12 \mathrm{~h}$ at $4{ }^{\circ} \mathrm{C}$ before surgery. In the blank control group, the same sized membranes were dipped in sterilize normal saline under 
the same conditions. After the scaffolds were transplanted into the defect, the buccal masseter and the skin were repositioned to cover the defect and sutured with 5-0 and 3-0 surgical silks, respectively. All animals received soft food and injections of preventive antibiotics for 3 days, followed by normal food and water. The rats were sacrificed after 1,2, and 4 weeks, and the mandibles were isolated for further study.

\section{Histology and immunohistochemistry}

The animals were sacrificed under anesthesia, and the specimens, including the first molar and its surrounding periodontal tissue, were separated, fixed in $4 \%$ paraformaldehyde for $48 \mathrm{~h}$, and decalcified in $12.5 \%$ ethylene diamine tetraacetic acid (EDTA, Solarbio) (pH 7.3-7.5) for up to 8 weeks. After dehydration and hyalinization, the specimens were embedded in paraffin. A series of buccal-lingual sections ( $5 \mu \mathrm{m}$ thick) paralleling the long axis of the teeth were obtained. Sections that passed through the center of the middle root of the first molar were stained with hematoxylin-eosin (HE) (Solarbio) and modified Masson's trichrome (Solarbio) and were then subjected to immunohistochemistry according to the manufacturer's instructions. The antibodies used were as follows: mouse monoclonal anti-bone sialoprotein (BSP)-II (1:100, Santa Cruz Biotechnology, Dallas, TX, USA), mouse monoclonal anti-Runt-related transcription factor 2 (Runx2) (1:200, Abcam, Cambridge, MA, USA), rabbit polyclonal anti-tumor necrosis factor (TNF)- $\alpha$ (1:100), anti-interleukin (IL)-1ß (1:200, Abcam), and anti-IL-10 (1:100, Abcam) primary antibodies. A biotin-labeled goat anti-mouse/rabbit IgG complex was the secondary antibody (SPlink detection kit; ZSGBBioTech, Beijing, China). Immunohistochemical staining was performed with a diaminobenzidine kit (ZSGB, Bio Tech).

\section{Histological observation and measurements}

Periodontal tissue regeneration was observed with a light microscope (Olympus, Tokyo, Japan). The area of newly formed alveolar bone was calculated by Image-Pro Plus 6.0 software (Media Cybernetics, Rockville, MD, USA). For the immunohistochemistry analysis, images were obtained with a light microscope (Olympus). The integrated optical densities of BSP II, TNF- $\alpha$, IL- $1 \beta$, and IL-10 positive stainings were measured by Image-Pro Plus 6.0 software, while Runx2positive cells were counted by microscope observation.

\section{Statistical analyses}

Statistical analyses were conducted with Prism version 6.01 software (GraphPad, La Jolla, CA, USA). Data were expressed as the mean \pm standard deviation. Differences in new alveolar bone area and immunohistochemical density between groups were evaluated by one-way ANOVA, and the mean value of each group was compared using the Student-Newman-Keuls (SNK) test. Statistical significance was accepted with a $P$ value less than 0.05 .

\section{Results}

\section{Isolation and identification of GMSCs}

Spindle-shaped cells grew out from the transplanted gingival pieces and reached $80-90 \%$ confluency at 10 to 14 days in the culture plates (Fig. 1 A1, A2). Colonies (stained with crystal violet) were formed by single-cell suspension after 15 days, and cells showed a fibroblast-like morphology (Fig. 1 A3). The cells cultured from the fibroblastic colony-forming units were negative for expression of the hematopoietic markers CD34 (9.6\%) and CD45 (4.8\%) and positive for expression of the MSC-associated surface markers CD90 (100\%), CD105 (99.9\%), and CD44 (100\%) (Fig. 1B). After induction with osteogenic medium for 28 days, the cultured cells exhibited multilayered growth, and calcium deposits stained with Alizarin Red were observed microscopically (Fig. 1C), indicating that the cultured cells showed the potential for osteogenic differentiation. After induction for 21 days with adipogenic medium, the cultured cells could produce microscopic fat droplets as demonstrated by Oil Red O staining (Fig. 1C), which indicated that the cultured cells could be induced to differentiate into adipocytes. Taken together, the above results verified that we successfully isolated GMSCs.

\section{Periodontal tissue regeneration in periodontal defects}

The goal of periodontal therapy is the complete regeneration of periodontal tissue (new alveolar bone, cementum, and inserted periodontal ligament), which remains a great challenge in the treatment of periodontitis. The regeneration of periodontal attachment requires not only alveolar bone formation but also cementum formation in which the newly formed periodontal ligament can be anchored. In this study, periodontal defects were created on the buccal side of the first molar in the left mandible of rats by a surgical method, and physiological saline, $\alpha$-MEM, GF-CM, GMSC-CM, or PDLSC-CM was transplanted with a resorbable bilayer membrane, as described in the "Methods" section. To evaluate the effects of CMs on periodontal tissue regeneration, a newly formed bone in the periodontal defects was observed and measured in low-magnification HE-stained histological sections (Fig. 2) and in high-magnification Masson-stained sections at 4 weeks (Fig. 4), and periodontal ligament and cementum regeneration were observed under high magnification in each group (Figs. 3 and 4).

At 1 week, the defect area of each group was well filled with collagen membrane. In the apical region, the membrane just reached the old alveolar bone. In the coronal region, the membrane was located beneath the gingival connective tissue (top panel of Fig. 2A). A layer of connective tissue infiltrated with inflammatory cells and 


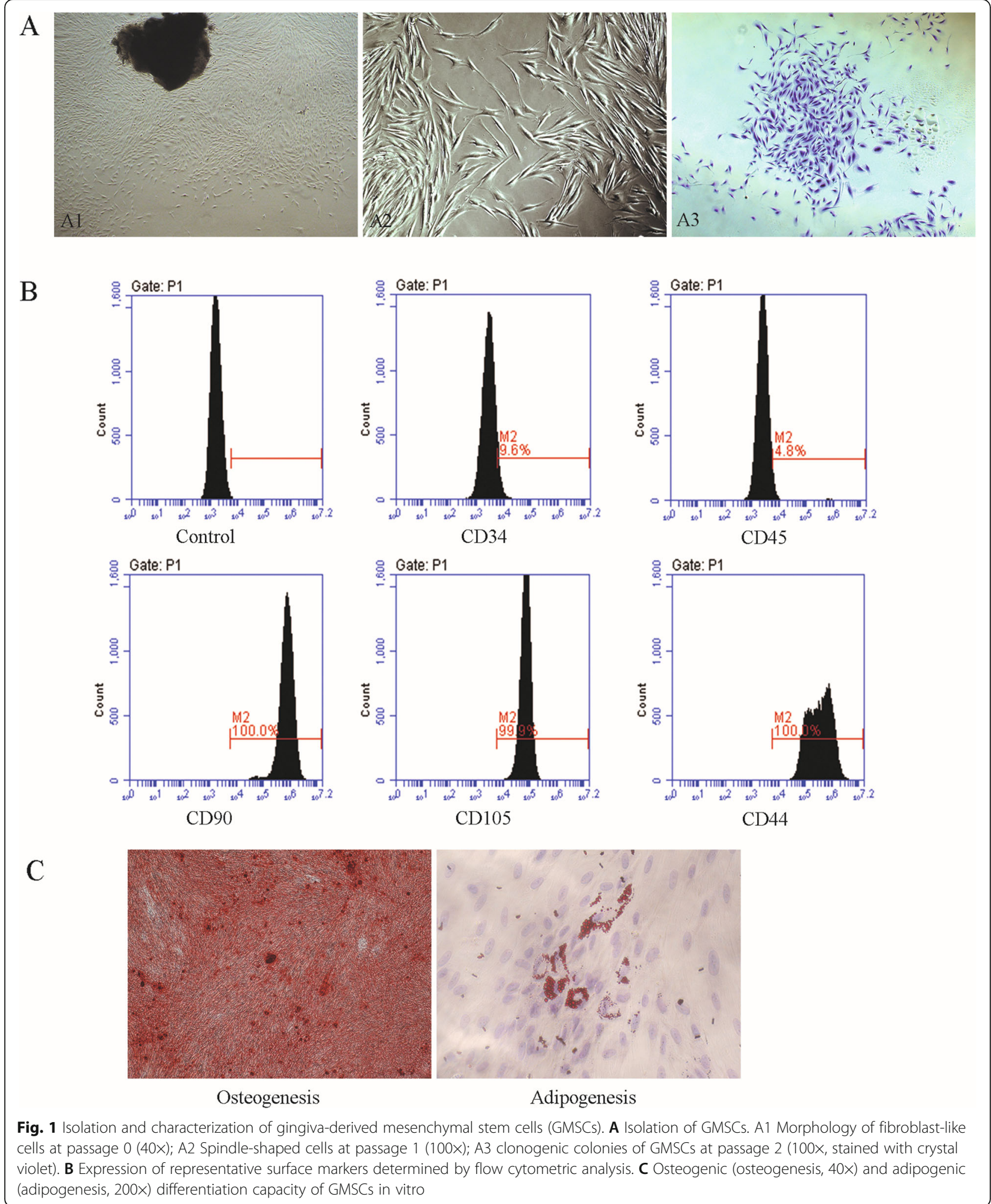

fibroblasts was observed between the root surface and the transplanted collagen membrane. These newly formed tissues were not well organized, and there was no much difference among the five groups. The root cementum was removed, and there was no newly formed cementum in any of the five groups at this time (top 


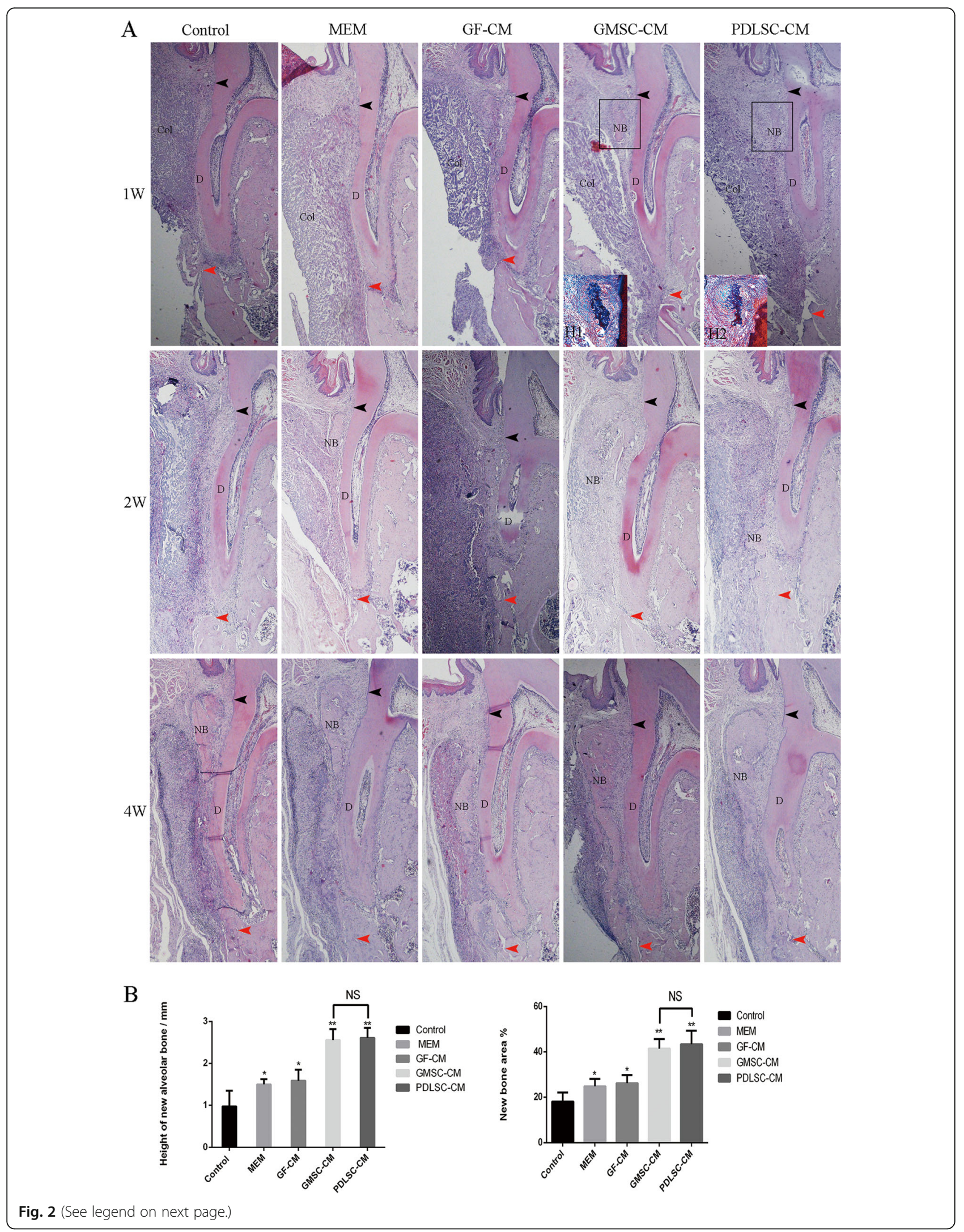


(See figure on previous page.)

Fig. 2 New alveolar bone formation observed by hematoxylin-eosin staining. A Representative images (40x) of new alveolar bone at 1, 2, and 4 weeks. NB, new alveolar bone; Col, collagen membrane; D, mandibular first molar tooth; black arrows, coronal limit of the defect; red arrows, apical limit of the defect. H1: Masson staining of GMSC-CM group (200x), H2: Masson staining of PDLSC-CM group (200x). B Statistical analysis of the area percentage and height of new alveolar bone in bone defects at 4 weeks. ${ }^{*} P<0.05$, ${ }^{*} P<0.01$ vs. control groups; NS, no

statistical significance

panel of Figs. 2A and 3). A few of specimens in GMSC$\mathrm{CM}$ and PDLSC-CM groups showed the islet-like new bone in the coronal region of the defect (top panel of Fig. 2A, Table 1; see Additional file 2). The newly formed bone-like tissue was distinguished which was demonstrated by Masson staining $(\mathrm{H} 1, \mathrm{H} 2$, embedded in the top panel of Fig. 2A; see Additional file 3 and Additional file 4).

At 2 weeks, the collagen membrane was partially absorbed, and the infiltration of inflammatory cells was reduced. Newly formed bone-like tissue was located in the coronal region of the defect and between the root surface and the collagen membrane (middle panel of Fig. 2A). In the GMSC-CM and PDLSC-CM groups, with the exception of the new bone formed in the coronal region, there was still more newly formed loose trabeculae bone growing coronally from the apical old bone (middle panel of Fig. 2A). New loose trabeculae bone could be observed in each group, but not in all specimens. The new bone formation observed in each group is listed in Table 1. The connective tissue, which separated the new bone from the root surface, became

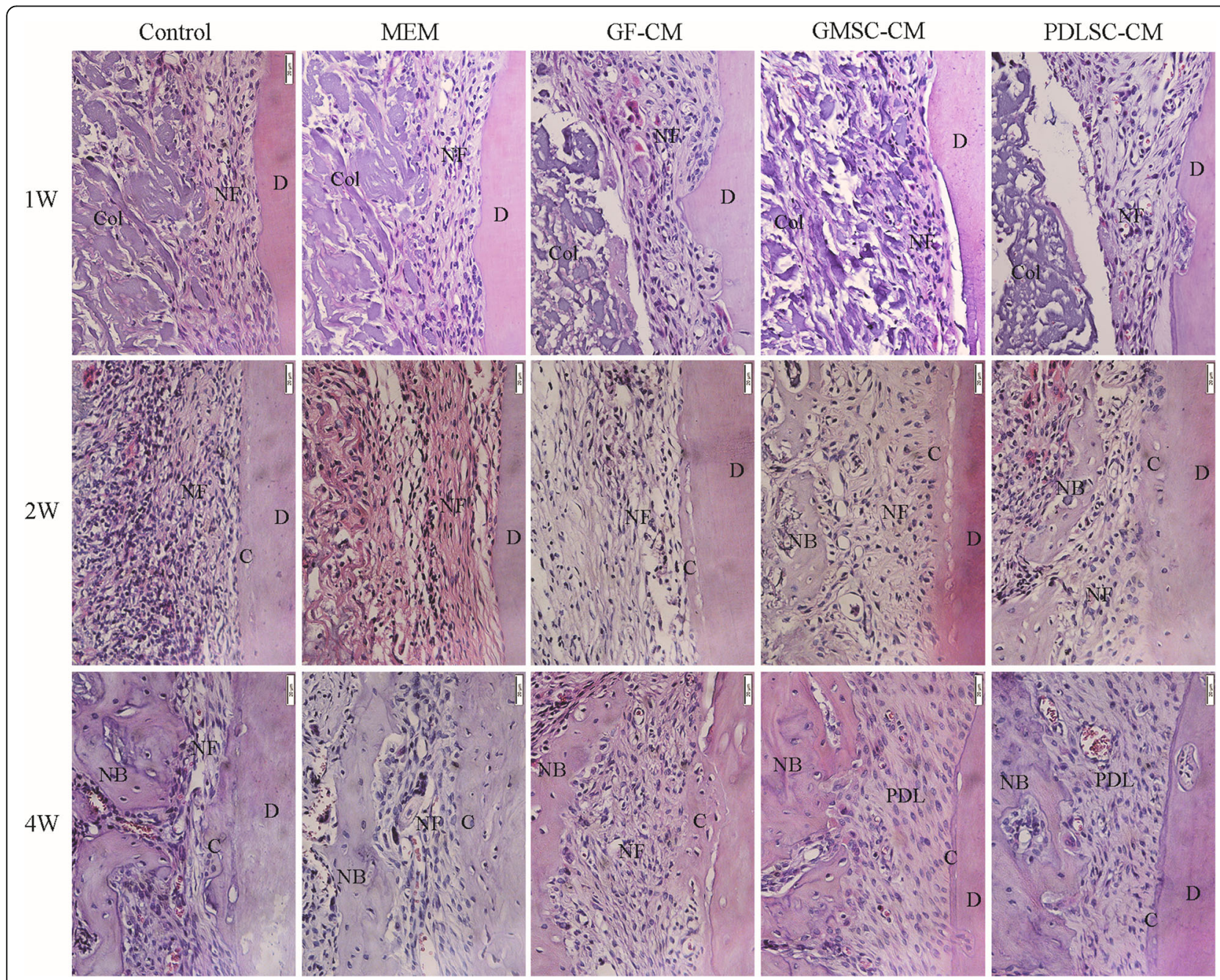

Fig. 3 Higher magnification images of new periodontal tissue formation observed by hematoxylin-eosin staining. Representative images (400x) of new periodontal tissue formation at 1, 2, and 4 weeks. NB, new alveolar bone; $D$, mandibular first molar tooth; NF, new fiber; $C$, new cementum; $\mathrm{PDL}$, new periodontal ligament 


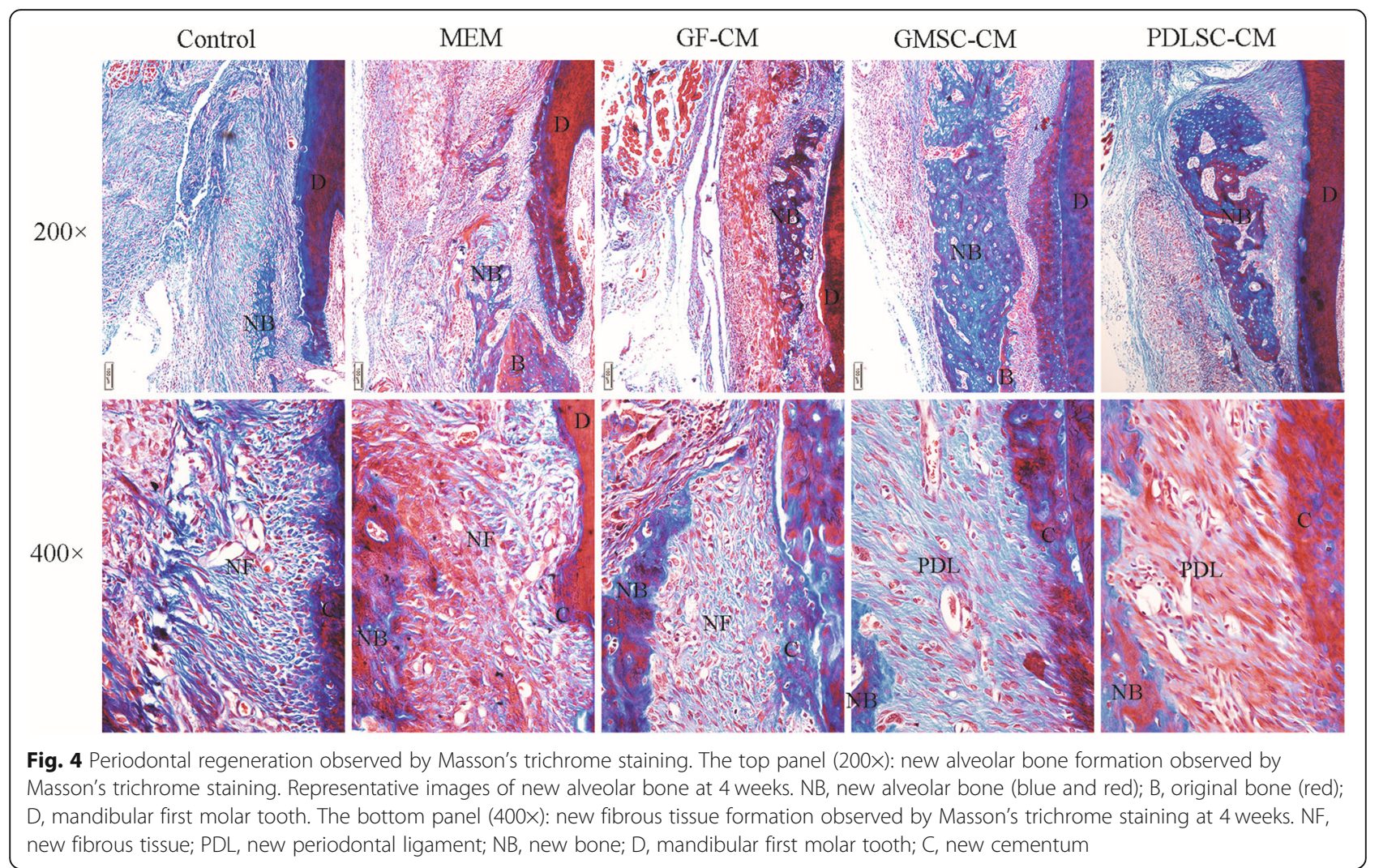

wider and more orderly when compared with 1 week. However, negligible differences in the morphology of the connective tissue were found among the groups (middle panel of Fig. 3). By high magnification, newly formed cellular cementum-like tissue could be observed along the root surfaces in each group, but not in all specimens. There were more new cementum formation specimens in the GMSC-CM and PDLSC-CM groups than in the other three groups. The new cementum formation allocated in each group was listed in Table 2 .

At 4 weeks, the implanted collagen membrane remained clearly visible, while inflammatory infiltration was further reduced (bottom panel of Fig. 2A). The newly formed bone became apparently wider and denser in the coronal region, while in the apical region, some specimens still showed porous trabecular bone and were mainly stained blue in the Masson-stained sections (top panel of Fig. 4), which indicated that the bone was still in the process of maturity.

Table 1 The distribution of specimens with new bone formation in each group

\begin{tabular}{llllll}
\hline Groups & Control & MEM & GF-CM & GMSC-CM & PDLSC-CM \\
\hline 1 week & 0 & 0 & 0 & 2 & 1 \\
2 weeks & 2 & 2 & 3 & 6 & 6 \\
\hline
\end{tabular}

In the GMSC-CM and PDLSC-CM groups, the height of the new alveolar bone was significantly increased, and the new bone almost fully filled the whole defect. All specimens showed bone formation, and there was more organized connective tissue between the newly formed bone and the root surface. No ankylosis, namely, direct boneroot contact, was found in our experiment. No significant differences in the area or height of neonatal alveolar bone were observed between the GMSC-CM group and the PDLSC-CM group. However, the area percentage and height of neonatal alveolar bone were significantly higher in both the GMSC-CM group and the PDLSC-CM group than those in the other three groups (Fig. 2B). New cementum-like tissue and periodontal fibers could be observed in most of the specimens. In the GMSC-CM and PDLSC-CM groups, periodontal fibers were inserted into the newly formed acellular cementum or cellular cementum, then oblique coronally and inserted into the newly

Table 2 The number of specimens with new cementum formation in each group

\begin{tabular}{llllll}
\hline Groups & Control & MEM & GF-CM & GMSC-CM & PDLSC-CM \\
\hline 1 week & 0 & 0 & 0 & 0 & 0 \\
2 weeks & 1 & 1 & 2 & 4 & 5 \\
4 weeks & 4 & 5 & 5 & 6 & 6 \\
\hline
\end{tabular}


formed alveolar bone (bottom panel of Figs. 3 and 4), which was similar to the periodontal structure in the intact lingual side. In the other three groups, the root surface was mainly covered by cellular cementum, and the connective tissue was less orderly aligned than those in the GMSC$\mathrm{CM}$ and PDLSC-CM groups. Also, there was always a very thin space between the root dentin and the newly formed cementum (bottom panel of Figs. 3 and 4).

\section{Expression of osteogenesis-related markers in periodontal defects}

Since the volume of regenerated periodontal tissue was dependent on the type of conditioned mediums and as it has been documented that CMs generated by MSC culture contains growth factors, cytokines, and other active substances through which MSC-CM can enhance bone regeneration $[17,18]$, it is conceivable that the promotion of osteogenesis/cementogenesis might explain the regenerative function of PDLSC-CM and GMSC-CM. Thus, we evaluated the effect of CMs on osteogenesis/cementogenesis by BSPII and Runx2 immunohistochemical staining. The results showed that at 1 week (Fig. 5A top panel), abundant yellow-brown BSPII-positive cells were observed in the marrow between the new bone in the PDLSC-CM and GMSC-CM groups. By 2 and 4 weeks, the BSPIIpositive cells had gradually diminished and were mainly observed at the trabecular edge of the new bone (Fig. 5A middle and bottom panel). Runx2-positive cells were also observed around the newly formed alveolar bone. The number of Runx2-positive cells in each group was higher at 2 weeks than at 1 week. However, by 4 weeks, the number of Runx2-positive cells had decreased in each group, and

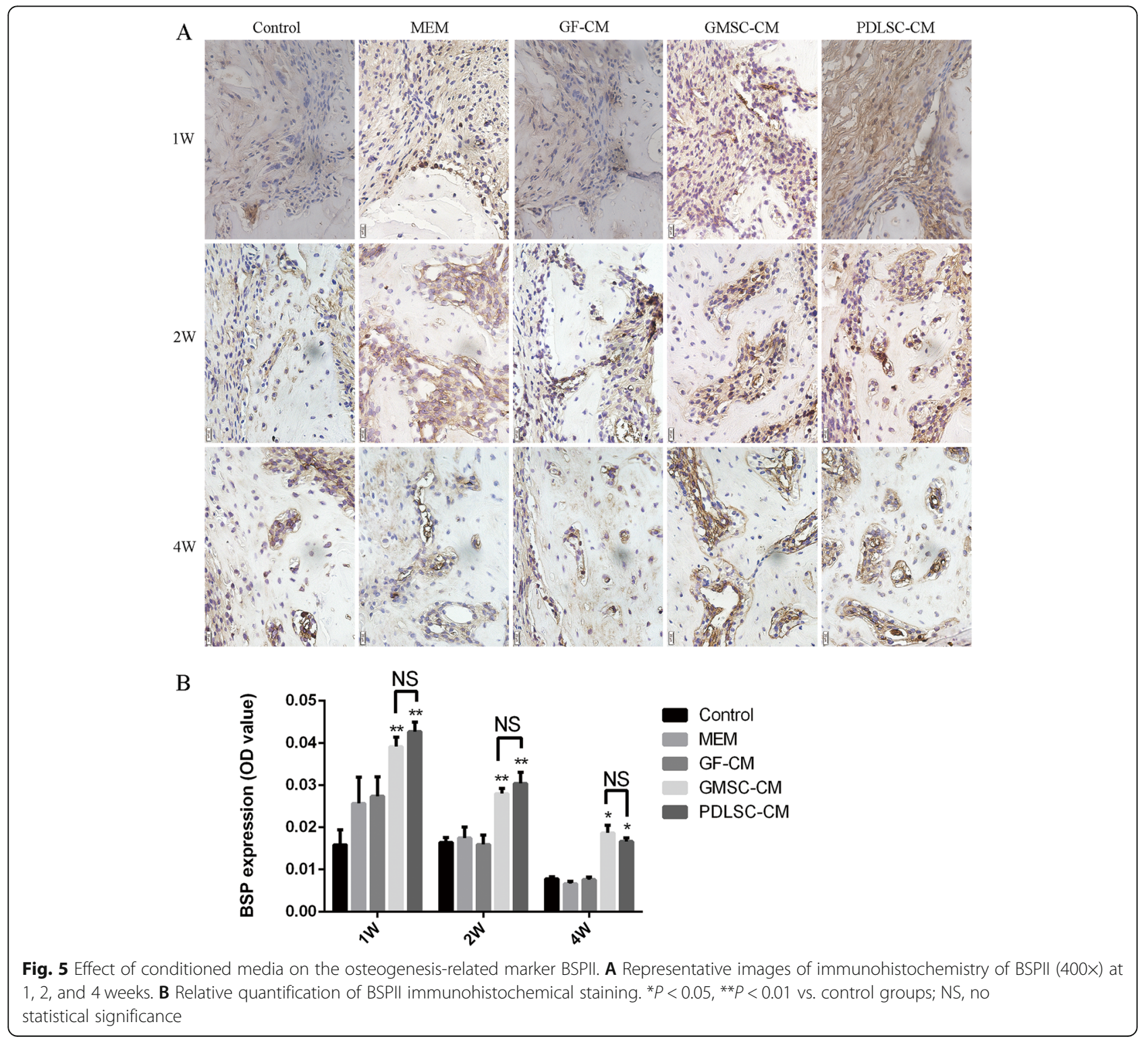




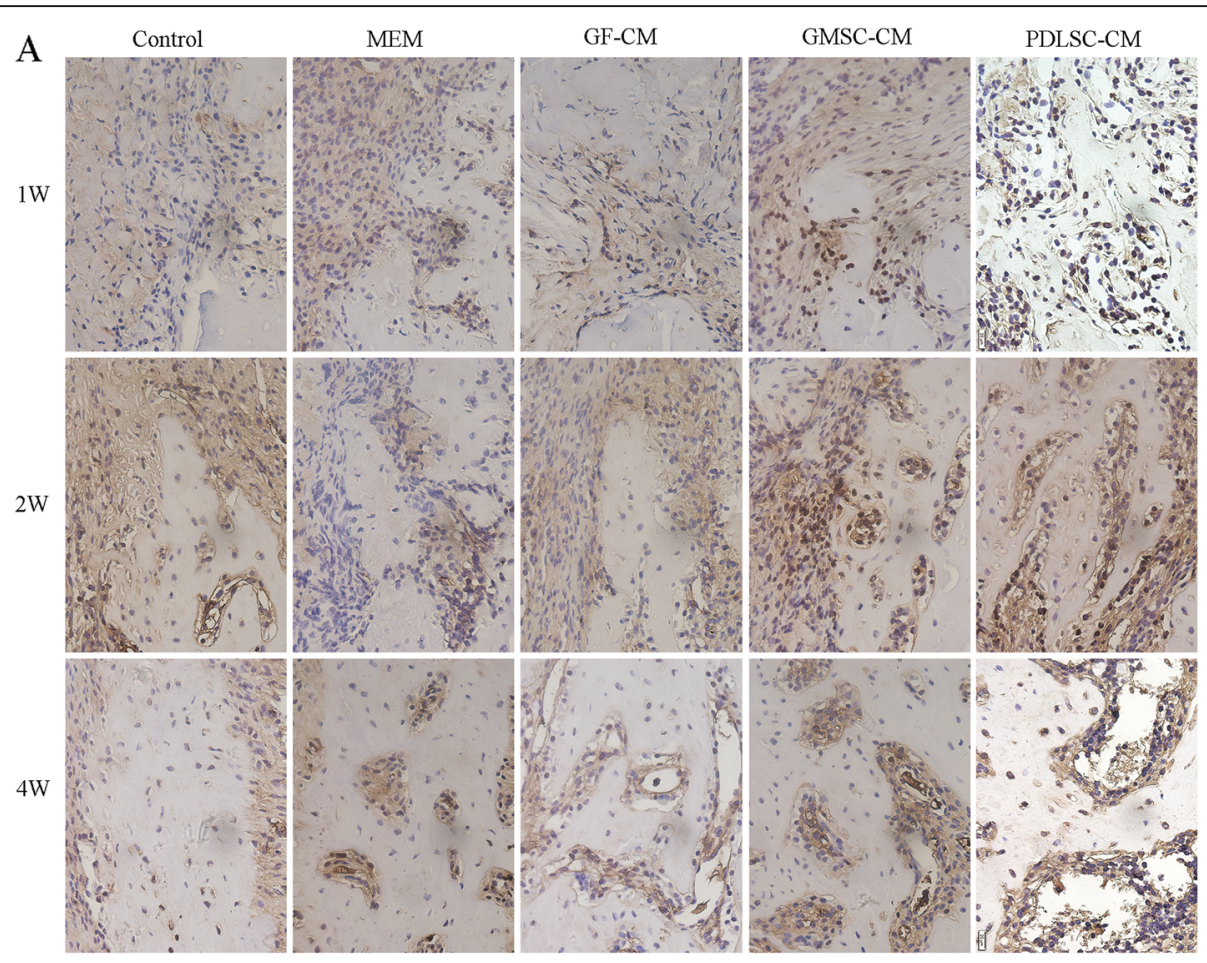

B

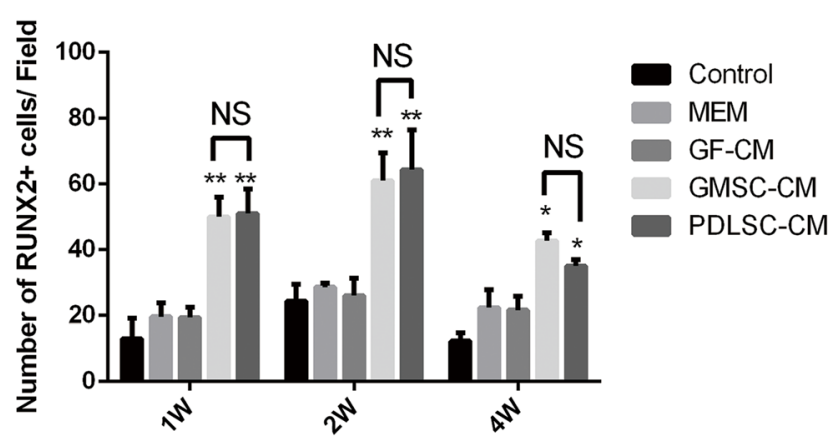

Fig. 6 Effect of conditioned media on the osteogenesis-related marker Runx2. A Representative images of immunohistochemistry of Runx2 $(400 \times)$ at 1,2 , and 4 weeks. B Relative quantification of Runx2 immunohistochemical staining. ${ }^{*} P<0.05,{ }^{*} P<0.01$ vs. control groups; NS, no statistical significance

these cells were mainly observed at the edge of the new trabecular bone (Fig. 6A).

At 1, 2, and 4 weeks, the GMSC-CM and PDLSC-CM groups exhibited significantly higher expression of BSPII (Fig. 5B) and Runx2 (Fig. 6B) than the other three groups $(P<0.05)$, while there were no significant differences between the GMSC-CM and PDLSC-CM groups.

\section{Inflammation modulation after CM transplantation}

PDLSC-CM has been documented to possess antiinflammatory properties, and some studies have shown that GMSCs have superior anti-inflammatory and immunomodulatory functions $[28,29]$. Wound healing and regeneration are greatly influenced by inflammation. Therefore, immunohistochemical staining for TNF- $\alpha$,
IL-1 $\beta$, and IL-10 was used to evaluate inflammatory modulation by GMSC-CM and PDLSC-CM at the surgical periodontal site. TNF- $\alpha$ (Fig. 7A) and IL-1 $\beta$ (Fig. 8A) presented almost the same staining results, and the positively stained cells were distributed in the defect area and along the inner side of the collagen membrane. More positively stained cells were found at 1 week than at 2 weeks within each group. At both 1 and 2 weeks, the expression levels of TNF- $\alpha$ (Fig. 7B) and IL-1 $\beta$ (Fig. 8B) were significantly lower in the GMSC-CM and PDLSC$\mathrm{CM}$ groups than in the other three groups, and there was no significant difference between these two groups. On the other hand, within each group, fewer IL-10-positive cells were found at 1 week than at 2 weeks (Fig. 9B). At 1 week, the GMSC-CM and PDLSC-CM groups exhibited 


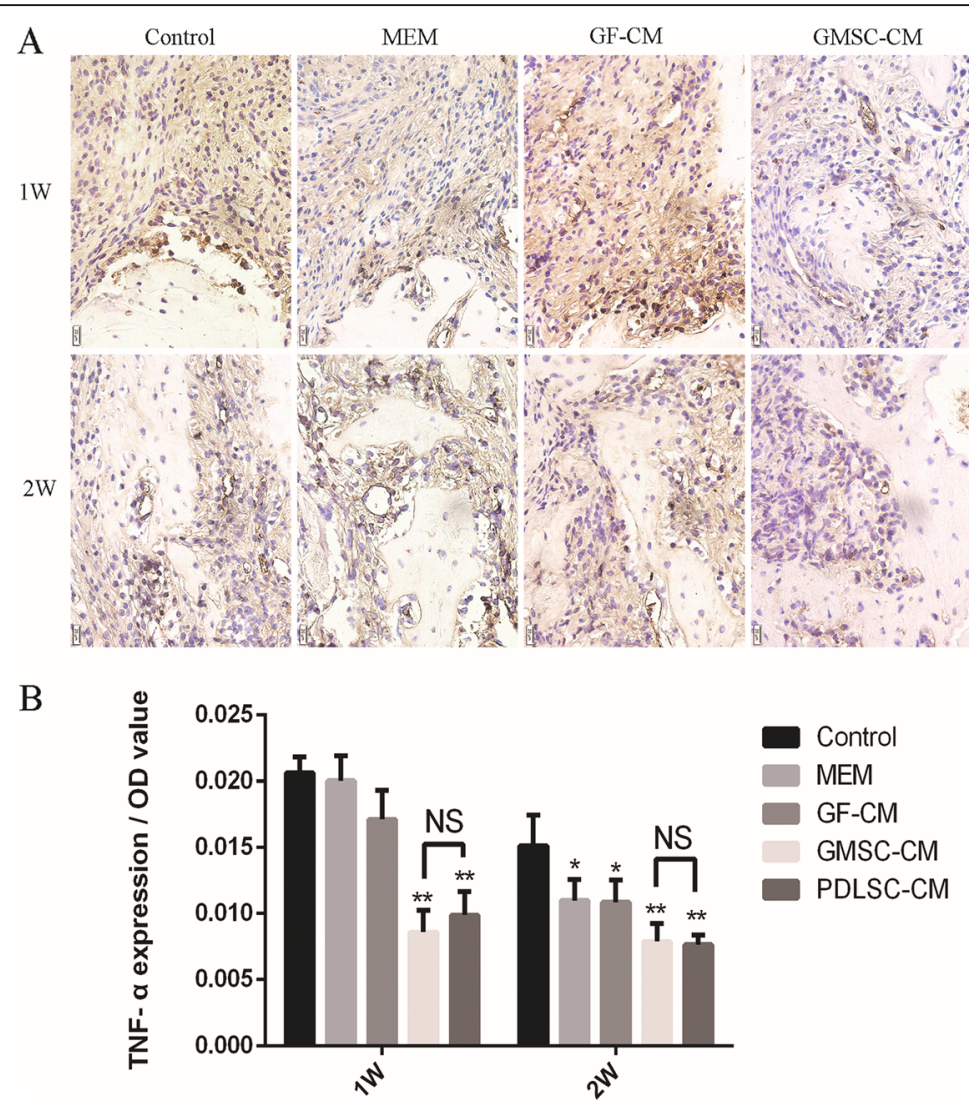

Fig. 7 Effect of conditioned media on the osteogenesis-related marker TNF-a. A Representative images of immunohistochemistry of TNF-a (400x) at 1 and 2 weeks. B Relative quantification of TNF-a immunohistochemical staining. ${ }^{*} P<0.05$, ${ }^{*} P<0.01$ vs. control groups; NS, no

statistical significance

significantly more IL-10-positive cells than the other three groups (Fig. 9B). Moreover, the GMSC-CM group showed higher expression of IL-10 than the PDLSC-CM group. At 2 weeks, the GMSC-CM group exhibited significantly higher expression of IL-10 than the other four groups. There was no significant difference between the PDLSC-CM group and the control, $\alpha-M E M$, and GF-CM groups (Fig. 9B). These results suggest that both PDLSC-CM and GMSC-CM transplantation reduce inflammation in healing tissues and that GMSC-CM may have superior ability than PDLSC-CM when anti-inflammatory potential is considered.

\section{Discussion}

The ultimate goal of periodontal treatment is to regenerate the destroyed tooth-supporting tissues to their original form, architecture, and function. The objective of the current study was to compare the regenerative potential of GMSC-CM and PDLSC-CM in a periodontal bone defect model. The results demonstrate that $\mathrm{CMs}$ derived from both GMSCs and PDLSCs can enhance periodontal tissue regeneration in periodontal defects created in mandibular first molars of Wistar rats. Furthermore, the effects of GMSC-CM on periodontal tissue regeneration were comparable to those of PDLSC-CM. Our results are in agreement with those of Nagata et al. [17], who showed that transplantation with a high concentration of PDLSC$\mathrm{CM}$ enhanced periodontal regeneration in rats.

Previous studies have indicated that MSC-CM, which contains multiple paracrine growth factors and cytokines secreted into the culture medium by stem cells, can be used to treat various degenerative conditions, including periodontal conditions $[15,38]$. The effects of MSC-CM include angiogenesis, immunomodulation, anti-apoptosis activity, cellular growth support, and chemoattraction [39-41]. Nagata et al. [17] were not the only group to apply MSC-CM to periodontal defects. Inukai et al. [38] and Kawai et al. [18] also reported that BMSC-CM promoted periodontal defect regeneration. In the above three studies, the authors used MSCs derived from different tissues. Although they all achieved periodontal tissue regeneration to some extent, the methods used to acquire MSCs were dependent on the donor resources available to the authors, and thus, we sought to identify more easily available stem cells to satisfy future applications. GMSC transplantation contributes to bone tissue regeneration, 


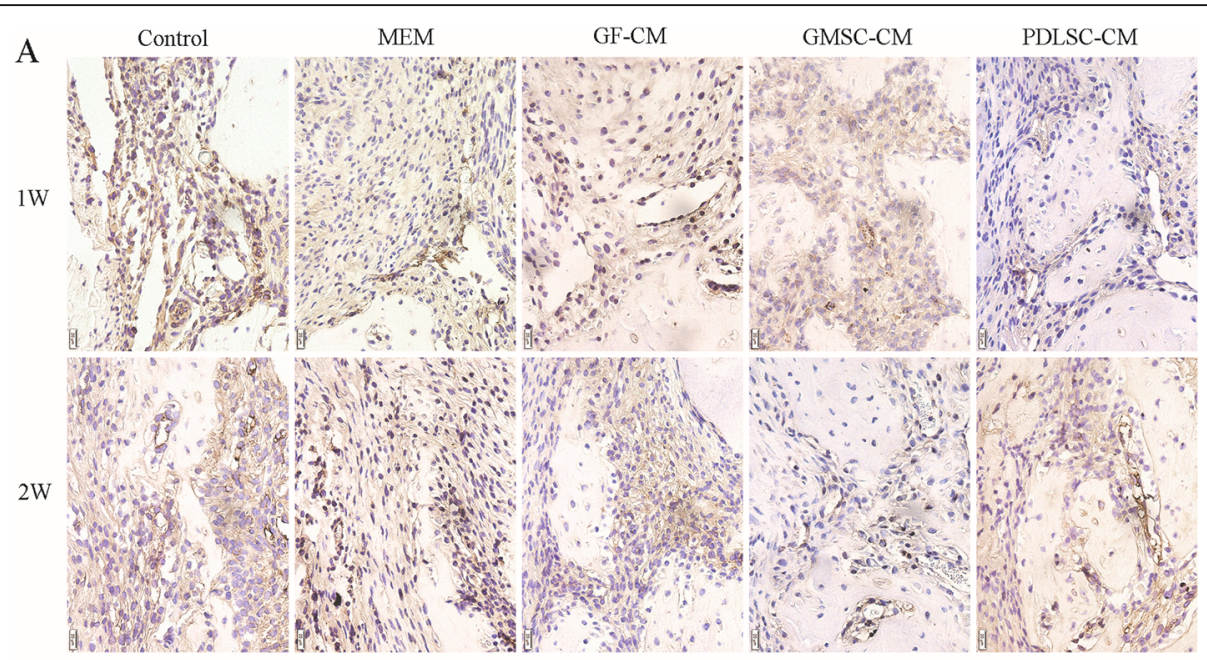

B

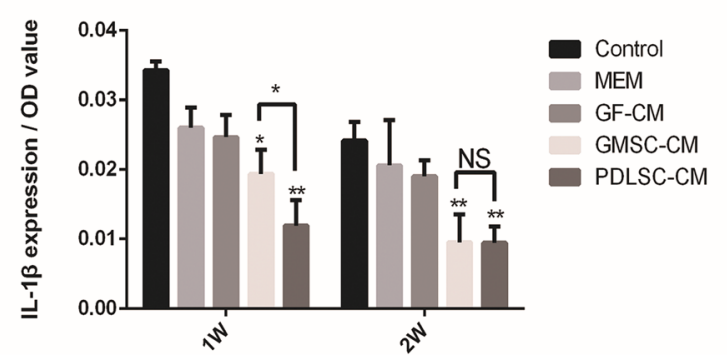

Fig. 8 Effect of conditioned media on the osteogenesis-related marker IL-1 $\beta$. A Representative images of immunohistochemistry of IL-1 $\beta$ (400X) at 1 and 2 weeks. B Relative quantification of IL-1 $\beta$ immunohistochemical staining. ${ }^{*} P<0.05,{ }^{* *} P<0.01$ vs. control group; NS, no statistical significance

indicating that GMSCs are a promising stem cell resource for bone regeneration [31, 32]. GMSCs are a promising source of stem cells because of their regenerative and immunomodulatory properties, capacity for scarless wound healing, easy isolation, and expansion ability [42]. However, as the CMs may differ according to the cell source [15], the function of GMSC-CM in periodontal regeneration needs to be confirmed. Our results shed light on the potential widespread applications of GMSC-CM in periodontal wound healing.

To explore the mechanism of periodontal tissue regeneration enhancement by GMSC-CM and PDLSC-CM, we further studied osteogenesis in periodontal defects. The GMSC-CM group, similar to the PDLSC-CM group, showed higher expression of osteogenesis-related markers, which demonstrated that CMs from MSCs may enhance periodontal tissue regeneration by promoting the osteogenic differentiation of bone progenitor cells in the wound region. The osteogenic differentiation process includes three stages of matrix formation: proliferation, maturation, and mineralization. Runx 2 protein is the first transcription factor required for the determination of osteoblast lineage; it is first detected in preosteogenic cells, upregulated in immature osteoblasts, and downregulated in mature osteoblasts [43]. BSP is mainly a bone matrix component derived from osteoblasts and is expressed in the late stage of differentiation [44]. Immunohistochemical analysis indicated that GMSC-CM significantly increased the levels of BSPII and Runx2 in periodontal defects and achieved the same effect as PDLSC-CM. We demonstrated that GMSC-CM promoted alveolar bone formation in the defect.

PDLSC-CM has been documented to possess antiinflammatory properties, and some studies have shown that GMSCs have superior anti-inflammatory and immunomodulatory functions $[28,29]$. Wound healing and regeneration are greatly influenced by inflammation. Periodontitis is clinically defined as inflammation associated with microorganisms and mediated by the host, which results in the loss of periodontal attachment. During periodontal bone resorption, inflammatory cytokines result in lymphocytes and fibroblasts producing receptor activator of nuclear factorkappa B (RANK) and activation of monocytes, which differentiate into macrophages and preosteoclasts [45]. Moreover, inflammatory cytokines combined with the RANK ligand induce preosteoclasts to differentiate into osteoclasts [46]. 


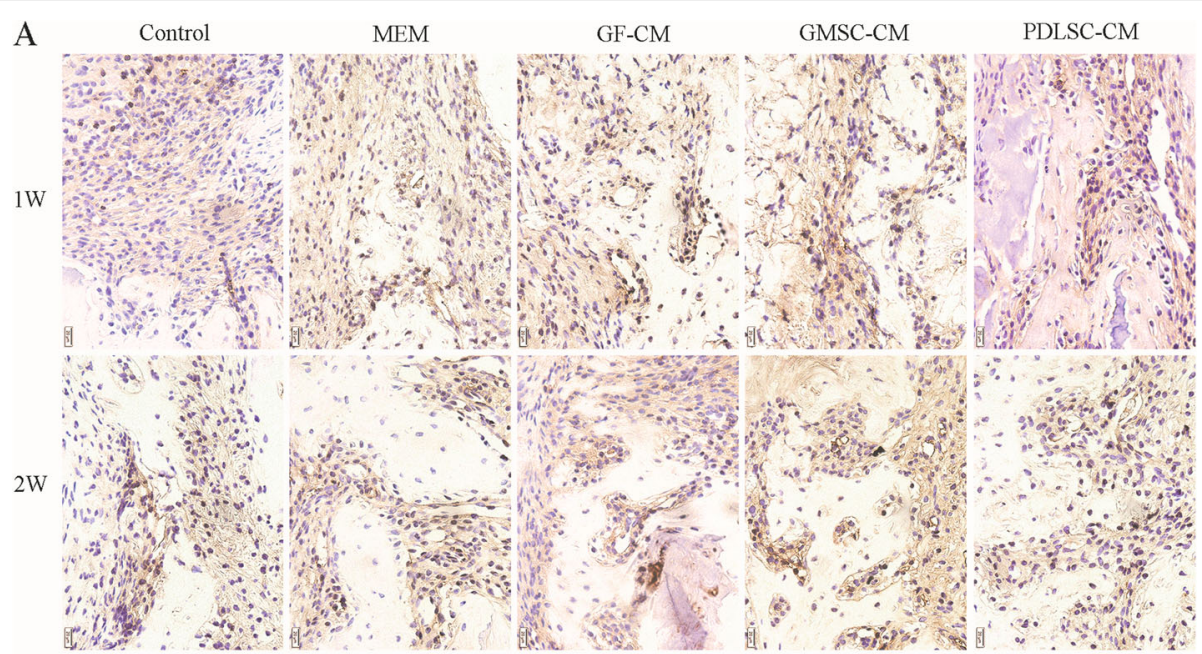

B

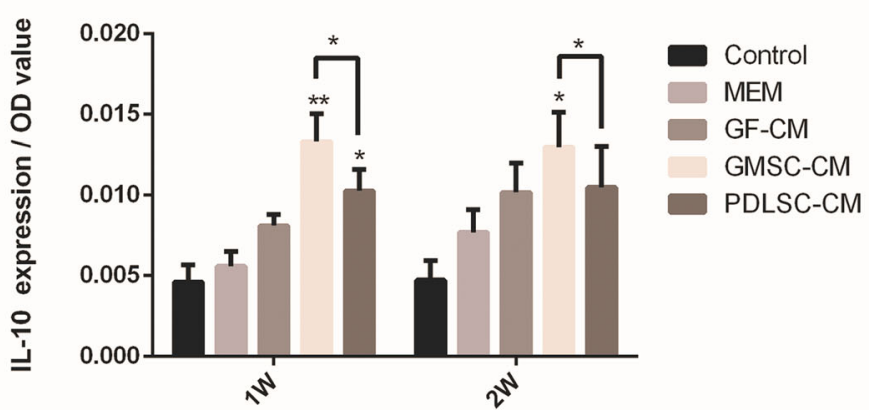

Fig. 9 Effect of conditioned media on the osteogenesis-related marker IL-10. A Representative images of immunohistochemistry of IL-10 (400x) at 1 and 2 weeks. B Relative quantification of IL-1 $\beta$ immunohistochemical staining. ${ }^{*} P<0.05$, ${ }^{*} P<0.01$ vs. control group

Much periodontal tissue destruction is ascribed to TNF- $\alpha$ and IL-1 activities [47, 48]. IL-10, as an anti-inflammatory cytokine, inhibits the functions of Th1 cells; reduces the secretion of proinflammatory cytokines, such as TNF- $\alpha$, IL1 , IL-2, IL-6, and IL-8; and promotes the production of protective antibodies [49]. IL-10 regulates proinflammatory cytokines and plays an important role in suppressing inflammatory and immune responses $[50,51]$. In the current experiment, our immunohistochemical analysis indicated that GMSC-CM and PDLSC-CM significantly decreased the levels of TNF- $\alpha$ and IL- $1 \beta$ and increased the level of IL-10 in periodontal tissue. Moreover, GMSC-CM significantly decreased the levels of TNF- $\alpha$ and IL-1 $\beta$, achieving the same effect as PDLSC-CM, but more significantly increased the level of IL-10 than PDLSC-CM. These results demonstrate a correlation among the suppression of TNF- $\alpha$ and IL-1 $1 \beta$, the promotion of IL-10, and periodontal regeneration. These findings support the conclusion that GMSC-CM enhances periodontal tissue regeneration by anti-inflammatory and immunoregulatory effects via TNF- $\alpha$ and IL- $1 \beta$ inhibition and IL-10 promotion.

To our knowledge, this study is the first to show that GMSC-CM enhances periodontal regeneration in vivo.
Furthermore, the amount of regeneration achieved with GMSC-CM was similar to that achieved with PDLSC-CM. Compared with PDLSC-CM, GMSC-CM has several advantages, including its anti-inflammatory and immunoregulatory capacities, abundant cell sources, and higher rate of cell proliferation. Compared with MSC transplantation, $\mathrm{CM}$ transplantation is advantageous for its lack of tumorigenicity and ease of storage and clinical application.

Several studies have reported the use of various MSC$\mathrm{CMs}$ to treat human skin wounds (adipose-derived stem cell-CM) [52], foot ulcers (amniotic MSC-CM) [53], and alopecia (adipose-derived stem cell-CM) [54] without any complications. However, further safety studies of $\mathrm{CM}$ transplantation are necessary.

\section{Conclusions}

Our results showed that GMSC-CM transplantation significantly promoted periodontal defect regeneration in rats and achieved the same effect as PDLSC-CM. The mechanism by which periodontal regeneration is promoted may be related to the regulation of inflammatory 
factors by MSC-CM and the facilitation of osteogenic differentiation of bone progenitor cells in the wound region. Thus, transplantation of GMSC-CM or PDLSC$\mathrm{CM}$ is a promising approach to inducing periodontal regeneration.

\section{Supplementary information}

Supplementary information accompanies this paper at https://doi.org/10. 1186/s13287-019-1546-9.

Additional file 1. Diagram of the buccal roots and the alveolar bone between the roots of rat first molar. DR; distal root of first mandibular molar; MR: mesial root of first mandibular molar; CR; central root of first mandibular molar; red square: coronal alveolar bone between the three roots; black square: the middle part of alveolar bone between the roots.

Additional file 2. Newly formed tissue in GMSC-CM and PDLSC-CM groups at 1 week (200X, HE staining). High (200X) magnification of Fig. 2A. NB: new alveolar bone; D: dentin.

Additional file 3. Newly formed tissue was observed by Masson staining in GMSC-CM at 1 week. B1:Low (40x) magnification. B2:High (200x) magnification of the tissue in the upper square, the newly formed calcified tissue was stained blue and the it seemed a little looser than the old alveolar bone; B3: High (200x) magnification of the tissue in the lower square. The old alveolar bone was stained red. NB: new alveolar bone; D: dentin; OB:old alveolar bone.

Additional file 4. Newly formed tissue was observed by Masson staining in PDLSC-CM at 1 week. B1:Low (40X) magnification. B2:High (200x) magnification of the tissue in the upper square, the newly formed calcified tissue was stained blue and the it seemed much looser than the old alveolar bone; B3: High (200x) magnification of the tissue in the lower square. The old alveolar bone was stained red. NB: new alveolar bone; D: dentin; OB:old alveolar bone.

\section{Abbreviations}

BSP: Bone sialoprotein; EDTA: Ethylene diamine tetraacetic acid; FBS: Fetal bovine serum; GMSC-CM: Gingival mesenchymal stem cell conditioned medium; HE: Hematoxylin-eosin; IL: Interleukin; MSCs: Mesenchymal stem cells; PBS: Phosphate-buffered saline; PDLSC-CM: Periodontal ligament stem cell conditioned medium; RANK: Receptor activator of nuclear factor-kappa; Runx2: Runt-related transcription factor 2; TNF: Tumor necrosis factor; aMEM: a-Minimal essential medium

\section{Acknowledgements}

The authors would like to express their gratitude to Miss Wenxiu Yuan, Miss Yixuan Fang, MS Hong An, and the staff at Shandong Provincial Key Laboratory of Oral Tissue Regeneration, Shandong Engineering Laboratory for Dental Materials and Oral Tissue Regeneration, for technical support.

\section{Authors' contributions}

QJ contributed to the cell culture and CM preparation, and ZC and HJ contributed to the PDLSC isolation. QJ, WX, ZH, WY, and LM contributed to the animal care and surgeries. QJ and WX contributed to the histological and immunohistochemical examination. QJ acquired the data, conducted the data analysis and interpretation, and contributed to the manuscript writing. SA and YP designed the experimental paradigm and proofread the manuscript. All authors read and approved the final manuscript.

\section{Funding}

This research was supported by the National Natural Science Foundation of China, No. 81771076 (to YPS).

\section{Availability of data and materials}

The datasets used and/or analyzed during the current study are included in this published article or available from the corresponding author upon reasonable request.

\section{Ethics approval and consent to participate}

The experiments were approved by the Shandong University Clinical Ethical Committee, and consent was provided by all donors (No. GR201407)

\section{Consent for publication}

Not applicable.

\section{Competing interests}

The authors declare that they have no competing interests.

\section{Author details}

'Department of Periodontology, School and Hospital of Stomatology, Shandong University, No.44-1 Wenhua Road West, Jinan 250012, Shandong, China. ${ }^{2}$ Shandong Provincial Key Laboratory of Oral Tissue Regeneration, No.44-1 Wenhua Road West, Jinan 250012, Shandong, China. ${ }^{3}$ Shandong Engineering Laboratory for Dental Materials and Oral Tissue Regeneration, No.44-1 Wenhua Road West, Jinan 250012, Shandong, China.

Received: 26 October 2019 Revised: 24 December 2019 Accepted: 29 December 2019 Published online: 03 February 2020

\section{References}

1. Page RC, Offenbacher S, Schroeder HE, Seymour GJ, Kornman KS. Advances in the pathogenesis of periodontitis: summary of developments, clinical implications and future directions. Periodontology 2000. 1997;14(1):216-48.

2. Pihlstrom BL, Michalowicz BS, Johnson NW. Periodontal diseases. Lancet. 2005;366(9499):1809-20.

3. D'Aiuto F. Treatment of periodontitis and endothelial function - NEJM [M]; 2007.

4. Kao RT, Nares S, Reynolds MA. Periodontal regeneration - intrabony defects: a systematic review from the AAP regeneration workshop. J Periodontol. 2015:86(2-s):S77-S104.

5. Hadlaq A, Mao J. Mesenchymal stem cells: isolation and therapeutics. Stem Cells Development. 2004;13(4):436-48.

6. Mushahary D, Spittler A, Kasper C, Weber V, Charwat V. Isolation, cultivation, and characterization of human mesenchymal stem cells. Cytometry Part A. 2017:93(1):19-31

7. Pittenger MF. Multilineage potential of adult human mesenchymal stem cells. Science (Washington D C). 1999;284(5411):143-7.

8. Jiang $Y H$, Jahagirdar BN, Reinhardt RL, Schwartz RE, Keene CD, OrtizGonzalez XR, et al. Pluripotency of mesenchymal stem cells derived from adult marrow. Nature (London). 2002;418(6893):41-9.

9. Zaher W, Harkness L, Jafari A, Kassem M. An update of human mesenchymal stem cell biology and their clinical uses. Arch Toxicol. 2014; 88(5):1069-82

10. Samsonraj RM, Raghunath M, Nurcombe V, Hui JH, Cool SM. Concise review: multifaceted characterization of human mesenchymal stem cells for use in regenerative medicine. Stem Cells Transl Med. 2017;6(12):2173-85.

11. Gnecchi M, Zhang Z, Ni A, Dzau VJ. Paracrine mechanisms in adult stem cell signaling and therapy. Circ Res. 2008;103(11):1204-19.

12. Liang $X$, Zhang $Y$, Ding $Y$, Tse $H$, Lian Q. Paracrine mechanisms of mesenchymal stem cell-based therapy: current status and perspectives. Cell Transplantation. 2013;23(9):1045.

13. Francisco V, Noemi E, Sandra C, Jose S, Roman PF. Mesenchymal stem cell secretome: toward cell-free therapeutic strategies in regenerative medicine. Int J Mol Sc. 2017:18(9):1852.

14. Nikbakht MR, Zarif MN, Oubari F, Mansouri K, Miri AT. Mesenchymal stem cell transplantation: immunobiology, therapeutic applications and challenges- a review article. Sci J Kurdistan Univ Med Sci. 2015;20(3):113-39.

15. Adiwinata PJ. Prospect of stem cell conditioned medium in regenerative medicine. Biomed Res Int. 2014;2014:1-14

16. Keshtkar S, Azarpira N, Ghahremani MH. Mesenchymal stem cell-derived extracellular vesicles: novel frontiers in regenerative medicine. Stem Cell Res Ther. 2018;9(1):63

17. Nagata M, Iwasaki K, Akazawa K, Komaki M, Morita I. Conditioned medium from periodontal ligament stem cells enhances periodontal regeneration. Tissue Eng A. 2016:23(9-10):367-77.

18. Kawai T, Katagiri W, Osugi M, Sugimura Y, Hibi H, Ueda M. Secretomes from bone marrow-derived mesenchymal stromal cells enhance periodontal tissue regeneration. Cytotherapy. 2015;17(4):369-81. 
19. Menicanin D, Mrozik KM, Wada N, Marino V, Shi S, Bartold PM, et al. Periodontal-ligament-derived stem cells exhibit the capacity for long-term survival, self-renewal, and regeneration of multiple tissue types in vivo. Stem Cells Dev. 2014:23(9):1001-11.

20. Maeda H, Tomokiyo A, Fujii S, Wada N, Akamine A. Promise of periodontal ligament stem cells in regeneration of periodontium. Stem Cell Res Ther. 2011;2(4):33

21. Liu Y, Zheng Y, Ding G, Fang D, Wang S. Periodontal ligament stem cellmediated treatment for periodontitis in miniature swine. Stem Cells. 2008; 26(4):1065-73.

22. Gronthos S, Mrozik K, Shi S, Bartold PM. Ovine periodontal ligament stem cells: isolation, characterization, and differentiation potential. Calcif Tissue Int. 2006;79(5):310-7.

23. Nagatomo K, Komaki M, Sekiya I, Sakaguchi Y, Ishikawa I. Stem cell properties of human periodontal ligament cells. J Periodontal Res. 2006; 41(4):303-10.

24. Gay IC. Isolation and characterization of pluripotent human periodontal ligament stem cells. Orthod Craniofac Res. 2007;21(2):330-4.

25. Zhang QZ, Nguyen AL, Yu WH, Le AD. Human oral mucosa and gingiva: a unique reservoir for mesenchymal stem cells. J Dent Res. 2012;91(11):1011-8.

26. Jin $\mathrm{SH}$, Lee JE, Yun JH, Kim I, Ko Y, Park JB. Isolation and characterization of human mesenchymal stem cells from gingival connective tissue. J Periodontal Res. 2015;50(4):461-7.

27. Santamaría Silvia S, Sanchez N, Sanz M, Garcia-Sanz JA. Comparison of periodontal ligament and gingiva-derived mesenchymal stem cells for regenerative therapies [J]. Clin Oral Investig. 2017;21(4):1095-102.

28. Gao Y, Zhao G, Li D, Chen X, Pang J, Ke J. Isolation and multiple differentiation potential assessment of human gingival mesenchymal stem cells. Int J Mol Sci. 2014;15(11):20982-96.

29. Zhang QZ, Su WR, Shi SH, Wilder-Smith P, Xiang AP, Wong A, et al. Human gingiva-derived mesenchymal stem cells elicit polarization of $M 2$ macrophages and enhance cutaneous wound healing. Stem Cells. 2010; 28(10):1856-68.

30. Chung E, Son Y. Crosstalk between mesenchymal stem cells and macrophages in tissue repair. Tissue Eng Regenerative Med. 2014;11(6):431-8.

31. Wang F, Yu M, Yan X, Wen Y, Zeng Q, Yue W, et al. Gingiva-derived mesenchymal stem cell-mediated therapeutic approach for bone tissue regeneration. Stem Cells Dev. 2011;20(12):2093-102.

32. Xu QC, Wang ZG, Ji QX, Yu XB, Yang PS. Systemically transplanted human gingiva-derived mesenchymal stem cells contributing to bone tissue regeneration [J]. Int J Clin Exp Pathol. 2014;7(8):4922-9.

33. Yu X, Ge S, Chen S, Xu Q, Zhang J, Guo H, et al. Human gingiva-derived mesenchymal stromal cells contribute to periodontal regeneration in beagle dogs. Cells Tissues Organs. 2013;198(6):428.

34. Rajan TS, Diomede F, Bramanti P, Trubiani O, Mazzon E. Conditioned medium from human gingival mesenchymal stem cells protects motorneuron-like NSC-34 cells against scratch-injury-induced cell death. Int J Immunopathol Pharmacol. 2017;30(4):383-94.

35. Francesca D, Agnese G, Domenico S, Ilaria M, Marcos C, Emanuela M, et al. Biotherapeutic effect of gingival stem cells conditioned medium in bone tissue restoration. Int J Mol Sci. 2018;19(2):329.

36. Du LQ, Yang P, Ge SH. Isolation and characterization of human gingivaderived mesenchymal stem cells using limiting dilution method. J Dental Sci. 2016;11(3):304-14.

37. Zhang C, Guo H, Yang C, Chen Q, Huang J, Liu L, et al. The biological behavior optimization of human periodontal ligament stem cells via preconditioning by the combined application of fibroblast growth factor-2 and A83-01 in in vitro culture expansion. J Transl Med. 2019;17:66.

38. Inukai T, Katagiri W, Yoshimi R, Osugi M, Kawai T, Hibi H, et al. Novel application of stem cell-derived factors for periodontal regeneration. Biochem Biophys Res Commun. 2013;430(2):763-8.

39. Dobroslav K. Secretion of immunoregulatory cytokines by mesenchymal stem cells. World J Stem Cells. 2014;6(5):552.

40. Madrigal M, Rao KS, Riordan $\mathrm{NH}$. A review of therapeutic effects of mesenchymal stem cell secretions and induction of secretory modification by different culture methods. J Transl Med. 2014;12(1):260.

41. Ratajczak MZ, Kucia M, Jadczyk T, Greco NJ, Wojakowski W, Tendera M, et al. Pivotal role of paracrine effects in stem cell therapies in regenerative medicine: can we translate stem cell-secreted paracrine factors and microvesicles into better therapeutic strategies? Leukemia. 2012;26(6):1166-73
42. Venkatesh D, Kumar KM, Alur J. Gingival mesenchymal stem cells. J Oral Maxillofacial Pathol. 2017;21(2):296-8.

43. Komori T. Regulation of osteoblast differentiation by Runx2. Adv Exp Med Biol. 2010;658(1):43-9.

44. Bianco P, Fisher LW, Young MF, Termine JD, Robey PG. Expression of bone sialoprotein (BSP) in developing tissues. Calcif Tissue Int. 1992;49(6):421-6.

45. Bartold PM, Cantley MD, Haynes DR. Mechanisms and control of pathologic bone loss in periodontitis. Periodontology 2000. 2010;53(1):55-69.

46. Cochran DL. Inflammation and bone loss in periodontal disease. Periodontol. 2015;79(8 Suppl):1569.

47. Assuma R, Oates T, Cochran D, Amar S, Graves DT. IL-1 and TNF antagonists inhibit the inflammatory response and bone loss in experimental periodontitis. J immunol (Baltimore, Md.: 1950). 1998;160(1):403-9.

48. Oates TW, Graves DT, Cochran DL. Clinical, radiographic and biochemical assessment of IL-1/TNF-a antagonist inhibition of bone loss in experimental periodontitis [J]. J Clin Periodontol. 2002;29(2):137-43.

49. Fiorentino DF, Zlotnik A, Mosmann TR, Howard M, O'Garra A. Pillars article: IL-10 inhibits cytokine production by activated macrophages. J. Immunol. 1991;147:3815-22 The Journal of Immunology, 2016, 197(5):1539-1546.

50. Sumer AP, Kara N, Keles GC, Gunes S, Koprulu H, Bagci H. Association of interleukin-10 gene polymorphisms with severe generalized chronic periodontitis [J]. J Periodontol. 2007:78(3):493-7.

51. Al-Rasheed A, Scheerens H, Rennick DM, Fletcher HM, Tatakis DN. Accelerated alveolar bone loss in mice lacking interleukin-10. J Dental Research. 2003;82:632-5.

52. Zhou B, Xu Y, Guo SL, Xu Y, Wang Y, Zhu F, et al. The effect of conditioned media of adipose-derived stem cells on wound healing after ablative fractional carbon dioxide laser resurfacing. Biomed Res Int. 2013; https://doi. org/10.1155/2013/519126.

53. Prakoeswa CRS, Natallya FR, Harnindya D, Thohiroh A, Oktaviyanti RN, Pratiwi KD, et al. The efficacy of topical human amniotic membranemesenchymal stem cell-conditioned medium (hAMMSC-CM) and a mixture of topical hAMMSC-CM + vitamin C and hAMMSC-CM + vitamin E on chronic plantar ulcers in leprosy:a randomized control trial. J Dermatolog Treat. 2018;29(8):835-40.

54. Fukuoka $\mathrm{H}$, Suga $\mathrm{H}$. Hair regeneration treatment using adipose-derived stem cell conditioned medium: follow-up with trichograms. Eplasty. 2015;15:e10.

\section{Publisher's Note}

Springer Nature remains neutral with regard to jurisdictional claims in published maps and institutional affiliations.

Ready to submit your research? Choose BMC and benefit from:

- fast, convenient online submission

- thorough peer review by experienced researchers in your field

- rapid publication on acceptance

- support for research data, including large and complex data types

- gold Open Access which fosters wider collaboration and increased citations

- maximum visibility for your research: over $100 \mathrm{M}$ website views per year

At $\mathrm{BMC}$, research is always in progress.

Learn more biomedcentral.com/submissions 